\title{
Editorial: Dr C Khandelwal
}

\section{Chiranjiva Khandelwal ${ }^{1,2}$}

Received: 9 January 2021 / Accepted: 9 January 2021 / Published online: 23 March 2021

(C) Association of Surgeons of India 2021

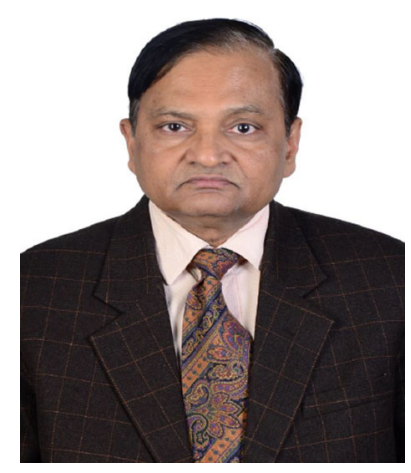

Our modern medical knowledge is based primarily on Western information. Like languages, diseases also vary geographically. Variations are not only in the type of diseases but also in clinical presentation and behavior.

There are many diseases in the tropics that senior surgeons manage with their experience but young surgeons may not have adequate knowledge and exposure to tropical surgery. Tropical surgery is not well covered in the standard textbooks and is usually not given much importance.

Chiranjiva Khandelwal

khandelwal3250@gmail.com

Narayan Medical College \& Hospital, Rohtas, Bihar, India

2 Surgical Gastroenterology \& Oncology, Paras HMRI Hospital, Patna, India
Surgery for tropical diseases is the domain of general surgeons. But, because of glamour and commercialisation, many young doctors are opting for specialties. Tropical surgery has taken a backseat and it is our responsibility to keep ourselves updated with the knowledge of wisdom from experienced surgeons in this field from within the country. That is why, IJS has come out with a special issue on tropical diseases. I am thankful to the editorial board for having given me the responsibility.

We have carefully chosen topics and authors; the authors have significant experience in the chapter they have contributed. We are grateful to all the authors who took time out of their busy schedule to contribute the article.

I am sorry for the unusual delay which was beyond my control.

We are sure this special issue of Indian Journal of Surgery will be very useful to all young surgeons as well as all practicing senior surgeons.

Publisher's Note Springer Nature remains neutral with regard to jurisdictional claims in published maps and institutional affiliations. 